\title{
A POLÍTICA EXTERNA SAUDITA DURANTE A PRIMAVERA ÁRABE (2010-2014)
}

\author{
Bruno Mendelski de Souza ${ }^{1}$
}

Emmanuel Brandolff Jardim²

\section{Resumo}

A Primavera Árabe vem transformando a geopolítica do Norte da África e do Oriente Médio. Dentre as potências regionais, a Arábia Saudita vem se destacando por ter uma atuação incisiva nos variados países atingidos pela Primavera Árabe. Tendo como base esse quadro regional, o presente artigo tem como objetivo problematizar a política externa saudita durante a Primavera Árabe. Utilizando-se de uma revisão da literatura sobre o tema, e do referencial teórico baseado no omnibalancing, inferimos que a política externa da Arábia Saudita, ao apoiar golpes e financiar grupos rebeldes durante a Primavera Árabe, é guiada não tanto pela segurança estatal, mas sim pela manutenção e legitimidade de seu próprio regime frente à sua população.

Palavras-Chave: Política Externa da Arábia Saudita, Primavera Árabe, Omnibalancing, Relações Internacionais do Norte da África e Oriente Médio, Política Internacional.

\begin{abstract}
The Arab Spring has changed the geopolitics of North Africa and the Middle East. Among the regional powers, Saudi Arabia has stood out for having an incisive performance in the various countries affected by the Arab Spring. Based on that regional context, this article aims to discuss the Saudi foreign policy during the Arab Spring. Using a literature review on the topic, and the theoretical framework based on the omnibalancing theory, we infer that the foreign policy of Saudi Arabia, supporting coups and finance rebel groups during the Arab Spring, is guided not so much by state security, but by maintaining and legitimacy of your own front regime to its population.
\end{abstract}

\footnotetext{
${ }^{1}$ Mestre em Relações Internacionais pela Universidade Federal do Rio Grande do Sul (2012). Graduado em Relações Internacionais pelo Centro Universitário La Salle (2009). Atualmente é Coordenador e Professor do Curso de Relações Internacionais da Universidade de Santa Cruz do Sul. É Membro do Grupo de Pesquisa Prisma (Pesquisas em Relações Internacionais de Santa Maria).
}

2 Bacharel em Relações Internacionais pela Universidade de Santa Cruz do Sul (UNISC). 
97 InterAção

Keywords: Saudi Arabia Foreign Policy, Arab Spring, Omnibalancing, International Relations of North Africa and the Middle East, International Policy.

\section{INTRODUÇÃO}

O conjunto de revoltas populares ocorridas em boa parte dos países árabes, iniciadas no final de 2010 e designadas como Primavera Árabe, vem alterando profundamente as dinâmicas internas e externas de seus países envolvidos. Internamente, a busca das populações locais por democracia e melhores condições de vida derrubou regimes (Tunísia, Líbia, Egito e Iêmen), conquistou avanços democráticos variados (Marrocos, Tunísia, Líbia, Iêmen, Arábia Saudita) e levou a guerras civis (Líbia e Síria). Externamente as potências regionais foram forçadas a atualizarem suas políticas externas de modo a melhor a lideram com este fenômeno.

Dentre as potências regionais, destaca-se a Arábia Saudita. Fatores como o seu imenso território, os dividendos e o poder geopolítico gerado por suas vastas reservas de petróleo, a questão simbólica de ter em seu Estado as duas cidades mais sagradas para o Islamismo (Meca e Medica respectivamente) e a capacidade de influenciar na política das nações árabes-muçulmanas atestam sua condição de fundamental player regional. Esta capacidade de influência tem mostrado-se muito importante para as novas dinâmicas geradas pela Primavera Árabe.

Dentro desta atuação externa saudita destacamos que sua força motriz não apresenta-se como a tradicional busca pela segurança estatal frente a ameaças externas. Por tratar-se de um regime autoritário e que necessita constantemente afirmar a legitimidade perante sua população, inferimos que a política externa saudita guia-se pela segurança e manutenção de seu regime governamental. Dessa forma, observa-se que as ações externas de Riad durante 
98 InterAção

a Primavera Árabe (apoio financeiro e político a grupos insurgentes e a governos) são calculadas tendo em consideração as ameaças internas e externas ao seu regime.

Nesse sentido, uma abordagem teórica tradicional, como o realismo (que não considera as variáveis internas nos cálculos de política externa) não apresenta-se como eficiente para esta análise. Torna-se imperativo o emprego de uma perspectiva teórica que não apenas contemple as variáveis internas, mas sim que disponha de um arcabouço capaz de articular estas com as indefinições do ambiente externo. A teoria do omnibalancing, desenvolvida por Steven David (1991) contempla estas questões. O autor ao examinar as políticas externas dos líderes do terceiro mundo ${ }^{3}$ pontua que estas são elaboradas a partir de um cálculo racional, tendo em conta as ameaças internas e externas ao regime governamental em questão. Assim, ao invés da tradicional preocupação com a segurança estatal, os líderes dos países em desenvolvimento procurarão equilibrar-se diante de revoltas, tentativas de golpes internamente, e externamente buscarão neutralizar Estados adversários capazes de influenciar domesticamente contra o seu regime.

Dito isso, o problema de pesquisa a ser respondido neste o artigo é: como o desejo de manutenção do regime de Riad guia a política externa saudita durante a Primavera Árabe? O nosso objetivo geral será problematizar a política externa saudita durante a Primavera Árabe. Procurar-se-á também entender suas motivações e mensurar o alcance de suas ações.

Para elucidar essas questões, o trabalho está divido em duas partes. $\mathrm{Na}$ primeira, será desenvolvida a ideia de omnibalancing, proposta por Steven David em 1991 através de seu artigo Explaining Third World Alignment.

\footnotetext{
${ }^{3}$ Como seu trabalho é do período da Guerra Fria, David (1991) utiliza o termo "terceiro mundo" para designar os países da periferia do capitalismo. Esse mesmo termo será mantido ao longo do artigo.
} 
99 InterAção

Posteriormente, utilizando-se do referencial teórico apresentado, analisar-se-á a política externa da Arábia Saudita para a Primavera Árabe.

\section{A TEORIA DO OMNIBALANCINGE A POLÍTICA EXTERNA DOS PAÍSES DE TERCEIRO MUNDO}

Desenvolvida por Steven David em 1991, no artigo “Explaining Third World Alignment", a teoria do omnibalancing procura explicar as decisões de política externa dos líderes dos Estados em desenvolvimento mundo a respeito das ameaças que estes enfrentam. Sua teoria possui duas inovações, comparado com abordagens mais tradicionais como a teoria da balança de poder. A primeira é considerar a esfera doméstica dos Estados como uma variável analítica relevante. A segunda é a constatação que as decisões de política externa dos países em desenvolvimento são tomadas, não tendo como base ameaças à segurança do Estado, mas sim a ameaças à segurança do regime de onde estão inseridos os líderes políticos. Para David:

Assim, enquanto a balança de poder se concentra nas necessidades do Estado para combater as ameaças de outros Estados, omnibalancing considera as ameaças internas e externas à liderança, e, como resultado ele altera fundamentalmente a nossa compreensão de por que os líderes do terceiro mundo se alinham e também providencia insights que explicam a vasta gama de comportamento do terceiro mundo (1991, 233, tradução livre).

A respeito do modo como os Estados em desenvolvimento se comportam diante das ameaças que enfrentam, David igualmente apresenta três reparações à teoria da balança de poder:

1. Ao invés de apenas equilibrar contra ameaças ou poder, os líderes dos Estados irão apaziguar, ou seja, alinharão-se com adversários secundários, para que possam concentrar seus recursos em adversários de primeira linha; 
$100 \mid$ InterAção

2. Os líderes do terceiro mundo buscam apaziguar ameaças secundárias de modo a conter aquelas que os pressiona mais. Mas no terceiro mundo, isto geralmente significa apaziguar outros Estados de modo a conter as ameaças domésticas mais imediatas e perigosas. Fazendo isto eles aplacam os aliados internacionais de seus oponentes domésticos.

3. Uma vez que o objetivo dominante dos líderes do terceiro mundo é permanecer no poder, eles vão, por vezes, proteger-se às custas dos interesses do Estado [grifos nossos] (1991, 235-236, tradução livre).

A respeito da constatação de que os líderes dos países em desenvolvimento guiam a política de seus Estados norteados por sua manutenção no poder, e não no tradicional interesse nacional, David (1991) ampara-se em duas premissas. Primeiramente ele defende que a legitimidade dos governantes dos países em desenvolvimento é frágil comparada com a dos países desenvolvidos, sendo necessário um intenso e permanente esforço para a manutenção no poder. Nesse sentido, David afirma que:

A legitimidade é provável que seja mais fraca para os líderes do terceiro mundo do que para líderes de outros lugares. Muitos regimes no terceiro mundo são baseados estritamente e chegaram ao poder através da força, e usam a supressão para permanecer no poder. Como eles não tem legitimidade, eles enfrentam ameaças constantes ao seu governo. (1991, 240, tradução livre).

O autor também pontua que razões como a construção artificial de muitos Estados, suas fronteiras arbitrárias, a tribalização, e a constante disputa pelo poder por grupos distintos, representam uma ameaça aos regimes e tornam a legitimidade dos governos dos países em desenvolvido fraca (David 1991).

Já a segunda premissa de David (de que os líderes dos Estados do terceiro mundo guiam sua política externa visando sua manutenção no poder e não o tradicional interesse nacional), é sustentada pelo olhar realista da 
$101 \mid$ InterAção

natureza humana, onde as decisão são sempre tomadas de forma racional, buscando o auto-interesse. No caso do omnibalancing, o objetivo central dos líderes políticos é a sua manutenção no poder. Para David:

Omnibalancing se baseia na suposição realista fundamental de que a política como a sociedade em geral, é regida por leis objetivas que tem suas raízes na natureza humana, ou seja, neste caso, o desejo dos líderes do terceiro mundo em sobreviver (1991, 237, tradução livre).

Além da visão comum junto ao realismo sobre a natureza humana, o omnibalancing compartilha outras concepções com esta teoria, como a visão de que a política internacional é focada em poder, interesses e racionalidade. Também comunga da ideia que a anarquia internacional torna os interesses vinculados a conflitos, e que o uso da força militar é sempre uma opção para os líderes dos Estados (David 1991). Já como pontos distantes entre o realismo e o omnibalancing, o autor coloca que:

A essência da diferença [entre omnibalancing e realismo] é que o omnibalancing afirma que o realismo deve ser ampliado para examinar as ameaças internas, além do foco em ameaças externas e capacidades, e que o líder do Estado, em vez do próprio Estado, deve ser utilizado como nível de análise (1991, 237, tradução livre).

Assim, para David, as decisões de política externa dos líderes dos países em desenvolvimento, representam uma calculada tomada decisão perante as ameaças internas e externas ao seu governo.

Outro ponto interessante na teoria do omnibalancing, e muito perceptível na agenda de alguns países em desenvolvimento, é a forte conexão das esferas doméstica e externa no que diz respeito às ameaças aos regimes. Segundo David, "uma interrelação entre ameaças internas e externas também caracteriza o terceiro mundo. Os líderes e insurgentes do terceiro mundo normalmente buscam apoio externo para promover os seus interesses" (1991, 240, tradução 
102 InterAção

livre). Estes interesses podem ser auxílio externo para se manter no poder ou ajuda para financiar grupos insurgentes em países terceiros. David afirma que a "fraqueza militar na maioria dos países do terceiro mundo aumenta a sua vontade em apoiar ou ajudar a suprimir as ameaças internas contra os seus vizinhos" (1991, 241, tradução livre). Neste sentido, a interferência na política doméstica de seus vizinhos, passa a ser uma estratégia eficiente e constante na agenda de política externa dos países em desenvolvimento, como veremos posteriormente, no caso da Arábia Saudita.

\section{A POLÍTICA EXTERNA SAUDITA PARA A PRIMAVERAÁRABE}

\subsection{CONDICIONAMENTOS DOMÉSTICOS E REGIONAIS À POLÍTICA EXTERNA SAUDITA}

O Reino da Arábia Saudita ocupa a maior parte da Península Arábica e é uma monarquia absolutista islâmica. "O país foi fundado pela dupla mobilização do poder militar tribal do clã Al-Saud e do movimento islâmico do Wahhabismo" Hinnesbusch (2003, 122, tradução livre). Esta doutrina islâmica conservadora (que Riad procura transformar em influência ideológica em sua política externa) constitui-se em uma das bases de legitimidade e sustentação do regime, juntamente com o simbolismo de encontrarem-se na Arábia Saudita, as duas cidades mais sagradas para o Islamismo (Meca e Medina respectivamente).

Mas esta construção de poder religioso é apenas uma das estratégias dos Al-Saud para se manter no poder, e garantir autonomia em sua política externa. Segundo Nonneman (2005), a aceitação dos regimes do Golfo Pérsico relacionase igualmente com elementos histórico-culturais como a prerrogativa de ser um provedor de qualidade de vida. No caso saudita, esse processo operacionaliza- 
103 | InterAção

se por meio dos recursos advindos do petróleo, que representam cerca de $80 \%$ da receita nacional e 45\% do Produto Interno Bruto do país (VISENTINI 2014). Esta grande fonte de divisas funciona então para evitar revoltas dos cidadãos e garantir a estabilidade do regime, tornando a Arábia Saudita um excelente exemplo de Estado rentista.

Enquanto que internamente o petróleo é responsável por financiar a sustentação do governo, externamente, ele concede autonomia econômica para que o Estado atue fortemente na política regional, a partir de financiamentos extraoficiais a aliados ou à grupos insurgentes que lutam contra regimes adversários (GAUSE 2011). Além disso, a riqueza petrolífera tornou possível a aliança político-militar com os Estados Unidos da América (EUA), vista como fundamental por Riad.

Em termos geopolíticos, a Arábia Saudita possui um ambiente regional complexo, e que contém dois eixos de ameaças ao Estado e ao regime (NONNEMAN 2005). O primeiro apresenta-se como as ameaças estatais e instabilidades contidas nos vizinhos Irã, Iraque, Iêmen, Chifre da África e Israel. O segundo consta nas ameaças ideológicas, como o antigo baathismo iraquiano, o xiismo revolucionário iraniano, o islamismo político moderado ou radical, e o pan-arabismo. A percepção da seriedade dessas ameaças é reforçada pelo grande e pouco habitado território saudita, disposto com fronteiras longas e difíceis de defender, e também pela existência de suas grandes reservas de petróleo (HINNEBUSCH 2003).

Este sentimento de vulnerabilidade favoreceu a busca por segurança externa, refletida na aliança com os EUA. Já Washington não apenas é dependente do petróleo saudita, como entende ser fundamental ter como aliado, uma das potências da região. Este alinhamento pode ser explicado pela ótica do omnibalancing, que preconiza que os líderes dos países de terceiro 
$104 \mid$ InterAção

mundo irão se alinhar com as potências externas mais propensas a mantê-los no poder (DAVID 1991).

A este equilíbrio entre ameaças internas e externas, Ennis e Momani (2013) acrescentam que a política externa saudita, tem historicamente sido descrita como cautelosa, pragmática e caracterizada por relações interpessoais, sendo gerenciada a partir da pressão interna e externa, procurando a todo custo manter a sobrevivência do regime e a supremacia regional. Nonneman (2005), em consonância com as premissas do omnibalancing afirma que os dois principais objetivos da política externa saudita são: (1) a segurança interna; e (2) a segurança externa.

Em termos de segurança interna, a Casa dos Al-Saud entende que a onda democrática da Primavera Árabe possa se transformar em um desafio ainda maior que os efeitos da Revolução Iraniana de 1979 sobre a sociedade saudita (VISENTINI 2014). Esta instabilidade política foi vivenciada (ainda que timidamente) pelos Al-Saud nos protestos em sua Província Oriental. A referida região é duplamente importante para Riad em razão de agrupar as maiores reservas de petróleo do país e por concentrar a maior parte da minoria xiita da Arábia Saudita (RIEGER 2013). Este grupo religioso acusa Riad de ser tratado como cidadãos de segunda classe, ao passo que o regime entende que os xiitas sauditas são passíveis de influência iraniana.

Nessa perspectiva, a elite saudita reagiu de três formas quando os protestos ocorridos na Província Oriental entre 2011 e 2013 tomaram forma. Inicialmente, Riad criou uma série de benefícios econômicos, sociais, de saúde e educacionais para a população, com o intuito de acalmar os revoltosos (ALRASHEED 2012). Posteriormente, reprimiu fortemente as manifestações, afirmando primeiramente que as mesmas não seriam toleradas, e subsequentemente prendendo e atirando contra os revoltosos (LAESSING 2011, 
$105 \mid$ InterAção

AL-JAZERA 2012, JAMJOOM 2013). Concomitantemente, a fim de deslegitimar estes protestos, e evitar que eles migrassem para áreas de maioria sunita, Riad focou-se no sectarismo, ligando as revoltas na Província Oriental, a um complô xiita iraniano para desestabilizar a Arábia Saudita (MAJIDYAR 2013).

Dentro desse contexto, um dos grandes temores da elite saudita, era de que os protestos xiitas vivenciados pelo vizinho Bahrein (distante apenas 25 quilômetros da Província Oriental) se espalhassem para o seu território. Tendo então a percepção dessa possível ameaça à manutenção de seu regime, e em conformidade com as ideias do omnibalancing, notamos que Riad não hesitou em adotar medidas mais extremas com o proposito de combater estes temores. Isto pode ser visto na decisão em isolar o seu território saudita do Bahrein (ao fechar durante três meses a ponte que liga os dois países), e ao invadir militarmente o Estado vizinho para por fim aos protestos ${ }^{4}$ (SAUDI GAZZETE, 2011).

No tocante a segurança externa do regime saudita, a política externa de Riad agiu de modo a garantir a estabilidade dos regimes aliados, sejam eles repúblicas (Tunísia, Egito e Iêmen) ou monarquias (Marrocos, Jordânia, Omã e Bahrein); ao passo que atuava tanto para desestabilizar os regimes inimigos (Líbia e Síria), quanto para reduzir a influência regional de seu principal rival, o Irã.

Dito isto, e partindo do pressuposto do omnibalancing de que os líderes dos países de terceiro mundo buscam nas ações de política externa de seus governos, equilibrar as suas ameaças internas e externas, de modo sempre a priorizarem a sua permanência no poder, destacaremos a partir de agora as principais ações externas de Riad durante a Primavera Árabe.

${ }^{4}$ Este ponto será aprofundado posteriormente na subseção 3.4 “Monarquias do Golfo Pérsico e lêmen”. 
106 | InterAção

\subsection{TUNÍSIA E EGITO}

A Primavera Árabe, iniciada em dezembro de 2010 na Tunísia apanhou a Arábia Saudita desprevenida. O regime ditatorial de Ben Ali era um aliado de longo tempo de Riad, importante na repressão a grupos islamistas (inspirados/apoiados pela Irmandade Muçulmana) (AL-RASHEED 2012). Com a breve e inesperada derrubada do regime tunisiano, a Arábia Saudita prontamente concedeu asilo à Ben Ali (OMRAN 2013). Posteriormente, com o processo de transição política, Riad passou a temer que uma vitória eleitoral de grupos afiliados à Irmandade Muçulmana na Tunísia, poderia indiretamente inspirar seus correligionários sauditas, ameaçando a estabilidade da Casa de Saud. Assim, Riad concedeu ajuda financeira e apoio político para estabilizar o novo governo, procurando excluir os islamistas do poder na Tunísia (ALANI apud KIRKPATRICK 2015).

Vemos desta forma então, que a política externa saudita para a Tunísia, mais do que guiar-se pela segurança estatal, orientou-se pelo desejo da estabilidade e manutenção de seu próprio regime político, possivelmente ameaçado com a ascensão ao poder do islamismo político da Irmandade Muçulmana. Esta instabilidade política e troca de regime vivenciada pela Tunísia, também acometeu o seu vizinho Egito.

Quando os egípcios iniciaram seus protestos em 25 de janeiro de 2011, a elite saudita interpretou este fenômeno como possível causador de duas ameaças à segurança saudita: internamente existia o medo que o islamismo transnacional da Irmandade Muçulmana (fortemente presente no Egito) 
$107 \mid$ InterAção

pudesse se tornar um desafio interno ao regime de Riad; e externamente havia o receio que seu o principal aliado árabe se direcionasse para a esfera de influência do Irã.

As vitórias de partidos ligados à Irmandade Muçulmana, na Tunísia (novembro de 2011) e no Egito (junho de 2012), contribuíram para este temor de Riad; sobretudo pelo fato de que os islamistas influenciados pelo grupo constituírem-se em uma importante organização oposicionista na Arábia Saudita desde o início dos anos 1990 (STEINBERG 2014). Além dessa ameaça interna, Riad atenta-se com uma possível aproximação de Cairo com Teerã, visto que "uma aproximação entre o Irã revolucionário e o Egito pós-Mubarak apresenta o risco de uma mudança dramática na dinâmica regional contra os interesses estratégicos sauditas" (SOUBRIER 2013, 5, tradução livre). Dessa forma, a diplomacia saudita rapidamente empenhou-se em estabelecer boas relações com o Conselho Supremo das Forças Armadas (que substituiu Mubarak), além de comprometer-se em ajudar o novo regime com 4 bilhões de dólares (GAUSE 2011).

Posteriormente, a decisão do então presidente Mursi de visitar o Irã em agosto de 2012 e a ida de Ahmadinejad ao Egito em fevereiro de 2013 reforçaram as desconfianças sauditas, e diante da percepção dessa nova conjuntura de ameaças externas e internas, o governo da Arábia Saudita não hesitou em apoiar o golpe militar de julho de 2013 que depôs o governo democraticamente eleito de Mursi. Conforme sugere a teoria do omnibalancing, "prestar ajuda a favor ou contra grupos insurgentes por um lado, ou apoiar ou suprimir golpes por outro lado, é um meio relativamente barato e eficaz de afirmar o seu poder". (DAVID 1991, 241, tradução livre). Logo em seguida ao golpe, a Arábia Saudita, Emirados Árabes Unidos e o Kuwait anunciaram uma ajuda de 12 bilhões de dólares ao novo regime egípcio (STEINBERG 2014). Por 
108 | InterAção

fim, de modo a apoiar a política anti-Irmandade Muçulmana adotada pelo novo regime do Cairo, que em dezembro de 2013 passou a considerar o grupo como uma organização terrorista, Riad, em março de 2014, também o fez.

\subsection{JORDÂNIA E MARROCOS}

Mesmo em países árabes periféricos, como a Jordânia e o Marrocos, a Arábia Saudita tem se empenhado em adotar uma política externa que vá de encontro aos seus interesses de estabilidade interna, apoiando a sobrevivência dessas monarquias, apesar dos fracos protestos vivenciados por ambas (STEINBERG 2014). Para o regime saudita, a manutenção do sistema monárquico nestas nações representa um freio na onda de democratização que atingiu estes países e que Riad teme que chegue em seu território. Desta forma, agindo racionalmente em prol de seu objetivo de manter-se no poder, conforme preconiza o omnibalancing, a elite saudita apoiou abertamente os regimes de Amã e Rabat.

Esse esforço pode ser visto no convite, à Jordânia e o Marrocos a se candidatarem a participarem do Conselho de Cooperação do Golfo ${ }^{5}$ (CCG), em 2011 (AL-RASHEED 2012). Esta ação reflete a preocupação saudita em tranquilizar ambas as monarquias de sua solidariedade logo após o início da Primavera Árabe, mas também em enviar uma mensagem para os movimentos de protesto. (STEINBERG 2014). Riad também valeu-se do seu poder econômico para fortalecer estes regimes aliados, ao coordenar em dezembro de 2011, um financiamento à projetos de desenvolvimento via CCG, no valor de 5 bilhões de dólares (STEINBERG 2014).

${ }^{5}$ Organização de Cooperação Regional criada em 1981 e integrada por Arábia Saudita, Emirados Árabes Unidos, Qatar, Kuwait, Bahrein e Omã. 
109 InterAção

A Arábia Saudita também compartilha com a Jordânia e com o Marrocos, o desejo de frear a atuação da Irmandade Muçulmana nestes países e na região. O desejo comum de derrubar o regime sírio pró-Irã, igualmente aproxima os interesses sauditas e jordanianos, onde “desde 2012, Jordânia e Arábia Saudita trabalham em conjunto apoiando os insurgentes na Síria" (STEINBERG 2014, 17, tradução livre). A partir do controle da fronteira jordaniana com a Síria, a Arábia Saudita tem conseguido melhor articular o seu apoio logístico e financeiro a grupos rebeldes sírios.

\subsection{MONARQUIAS DO GOLFO PÉRSICO E IÊMEN}

A política externa saudita para as monarquias do Golfo Pérsico (Kuwait, Emirados Árabes Unidos, Bahrein, Catar e Omã) durante a Primavera Árabe foi desempenhada tendo em conta a atuação do CCG, e visando a sua tradicional busca por segurança interna e segurança externa (NONNEMAN 2005). A segurança interna reflete-se no deseja da conservação do status quo das monarquias do Golfo Pérsico diante dos protestos da Primavera Árabe, visando a estabilidade da monarquia absolutista sunita saudita (VISENTINI 2014).

O segundo objetivo (que interliga-se com o primeiro) consiste em conter o aumento de poder regional de seu maior rival, o Irã. Este desejo deriva do temor que Teerã esteja procurando desestabilizar as monarquias do Golfo Pérsico, via apoio às populações xiitas destes países. $O$ regime saudita preocupa-se que por fim, o regime persa se transforme em fomentador do islamismo político xiita revolucionário nos países do Golfo Pérsico, aproveitando-se do descontentamento das populações xiitas locais (SOUBRIER 2013). 
$110 \mid$ InterAção

Nesta região, os protestos da Primavera Árabe atingiram além da Arábia Saudita, Omã e o Bahrein. De modo a amparar o governo de Omã e impedir maiores instabilidades em seu regime, Riad, prometeu em março de 2011 (juntamente para o Bahrein) 20 bilhões de dólares em ajuda (MURPHY 2011), refletindo a costumeira estratégia saudita de conceder volumosas somas de dinheiro de modo a evitar qualquer tipo de instabilidade nos regimes aliados. Segundo Rieger:

O regime de Al-Kalifa [Bahrein] e o Sultanato [Omã] tem muito menos meios financeiros para comprar a estabilidade do regime através de programas de gastos em larga escala do que os outros Estados do CCG. A Arábia Saudita, a qual provavelmente irá contribuir com a maior parte dos programas de ajuda financeira intra-CCG, está mais do que pronta para investir largas somas para garantir a estabilidade do regime de seus Estados companheiros do CCG (2013, 7, tradução livre).

Acerca do Bahrein, a conjuntura política envolvendo esta pequena nação, caracterizou-se por englobar as duas principais demandas da política externa saudita: a segurança interna e a segurança externa. Sob a primeira, a real ameaça de queda do regime do Bahrein despertou em Riad o medo que a revolta xiita neste país levasse a um spillover dos protestos em áreas xiitas de seu reino (RIEGER 2013). Também havia o receio saudita que a queda de um regime monárquico sunita conduzisse a uma maior insatisfação interna de seu governo. De acordo com Rieger: “com a potencial derrubada de um regime monárquico árabe, particularmente em sua vizinhança imediata, a legitimidade interna da própria monarquia saudita poderia ter sido cada vez mais contestada" (2013, 6, tradução livre)

De forma interligada a segurança interna, Riad constatou que sua segurança externa também estaria ameaçada com a possível perda de influência no Bahrein para o rival Irã, em caso de queda do referido regime sunita e sua subsequente substituição por um xiita pró-Irã. Este hipotético crescimento 
$111 \mid$ InterAção

geopolítico iraniano também é entendido como uma ameaça interna à Riad, uma vez que a elite saudita entende que os protestos no Bahrein e na Província Oriental da Arábia Saudita foram orquestrados pelo Irã de modo a desestabilizar os regimes sunitas locais (STEINBERG 2014).

Este contexto regional de ameaças internas e externas, levou o regime dos Al-Saud à atitude extrema de intervir militarmente no Bahrein, em março de 2011, tendo como base o CCG, e contando com uma pequena participação dos Emirados Árabes Unidos. Segundo David (1991), as escolhas racionais das elites determinam as políticas, ou seja, a sua avaliação de onde a ameaça é maior em um momento particular. Para a elite saudita, a sua maior ameaça durante o momento da crise política Manama seriam os reflexos da queda deste governo na estabilidade interna saudita, o que justifica o ato bélico. Também percebemos nesta ação as prerrogativas do omnibalancing de que a política internacional é focada em poder, interesses e racionalidade e de que o uso da força é sempre uma opção para os chefes de Estado (DAVID 1991).

Outrossim, a intervenção e o sucesso da mesma, igualmente significam um maior controle e influência saudita diante do estratégico Bahrein. "A ajuda financeira, a invasão militar e o apoio político fazem Manama cada vez mais dependente de Riad, tornando o Bahrein em um protetorado de facto da Arábia Saudita" (STEINBERG, 2014, 19). Desta forma, ao combinar ajuda financeira com intervenção militar, a diplomacia saudita saiu-se bem sucedida perante à ameaça interna que a instabilidade do Bahrein afetasse a legitimidade doméstica de seu reino, e à ameaça externa representada pelo possível aumento de poder do inimigo Irã sob o vulnerável Bahrein.

Já sobre o vizinho Iêmen (o mais pobre país árabe), Riad possui três preocupações relativas à sua segurança: à manutenção de um governo aliado e distante da influência iraniana, e o combate a dois grupos que aumentaram o 
112 InterAção

seu poder em razão do caos gerados pela Primavera Árabe: o braço iemita da Al-Qaeda na Península Arábica, e os xiitas zaiditas Houthis ${ }^{6}$ (vistos pelos sauditas como aliados do Irã). As incertezas políticas geradas pela Primavera Árabe no Iêmen deram condições para que ambos os grupos ganhassem espaço e controlassem partes do território iemita.

No início das revoltas populares no Iêmen, Riad ao mesmo tempo que apoiava o então presidente Ali Saleh, buscava garantir uma influência sobre a oposição (ENNIS e MOMANI 2013). Com a renúncia de Saleh e a eleição em fevereiro de 2012 de Abd Hadi como novo presidente, a Arábia Saudita manteve a sua política de generosas doações financeiras de modo a garantir sua influência política, prometendo 3,25 bilhões de dólares para auxiliar o novo governo do Iêmen a combater a Al-Qaeda neste país (Mc DOWALL 2012).

Tamanha quantia justifica-se pela forte ameaça que o grupo extremista representa para a estabilidade do regime da Casa de Saud e pelo fato de estar localizada tão próxima no Iêmen. A Arábia Saudita já sofreu vários atentados terroristas executados pela Al-Qaeda na Península Arábica, e seu regime é considerado um grande inimigo da rede terrorista. Esta ameaça é muito bem descrita pelo príncipe saudita Turki bin Faisal Al Saud $(2013,4)$ que afirma: “um Iêmen cada vez mais instável representa uma ameaça de segurança muito real, devido ao potencial de células terroristas que podem ser criadas lá. [O país] tem sido uma arena para as operações da Al-Qaeda, desde que a Al-Qaeda estabeleceu campos de treinamento lá na década de 1990". A instabilidade gerada pela Primavera Árabe no Iêmen apenas aumentou a atuação do grupo no país, que passou a controlar parte do território iemita; além de declarar guerra aos Houthis (NG e AARON 2011).

${ }^{6} 0$ Zaidismo é um ramo do xiismo que é encontrado somente no norte do lêmen. Houthis são um grupo rebelde de orientação zaidista que atua sobretudo no norte do lêmen. 
$113 \mid$ InterAção

Paralelamente à Al-Qaeda, os Houthis, também contribuem para a fragmentação do Iêmen, e são fortemente acusados de receber apoio iraniano, situação negada pelo Irã, mas endossada por parte dos pesquisadores do tema como Schmitt e Worth (2012). Um possível Iêmen controlado por um regime Houthi xiita, representa uma inter-relação de ameaças internas e externas à Arábia Saudita, conforme preconiza o omnibalancing (DAVID 1991). Domesticamente, Riad teme que o islamismo político xiita dos Houthis chegue ao seu território e constitua-se em um desafio á legitimidade do seu regime; externamente, há o temor que o Irã se fortaleça ao ganhar mais um aliado, de modo a representar uma ameaça à Arábia Saudita.

Diante dessas ameaças, a Riad tem agido de duas formas. Inicialmente, o regime saudita, após a tomada da capital Sana pelos Houthis, suspendeu a bilionária ajuda que presta há décadas, ao governo iemita, de modo a enfraquecer a operacionalidade governamental iemita, visto que o país é dependente do apoio externo saudita para funcionar (BAYOUMY; GHOBARI, 2014). Há décadas a diplomacia saudita tem se valido de volumosas ajudas econômicas para garantir a sua influência sobre o Iêmen (HILL e NONNEMAN, 2011). Nesse sentido, ao cortar esse subsídio, a Arábia Saudita visa enfraquecer a operacionalidade governamental iemita, visto que o país é dependente do apoio externo saudita para funcionar. Igualmente, a Arábia Saudita vem estreitando relações com líderes tribais iemitas de modo que estes voltem-se contra os Houthis (NICHOLS, 2014).

\subsection{LÍBIA E SÍRIA}

O regime líbio de Muammar Kadaffi foi historicamente um adversário político para a Casa dos Al-Saud, procurando tanto constranger e colocar em 
$114 \mid$ InterAção

xeque a legitimidade do regime de Riad. Segundo Rieger, "por quatro décadas, Kadaffi havia tentado publicamente embaraçar o regime dos Al-Saud e por em xeque a sua legitimidade" $(2013,13)$. Ainda de acordo com o autor, "as tentativas líbias de assassinar o então príncipe saudita e governante de fato, Abdullah em 2003, irremediavelmente envenenaram as relações entre os AlSaud e Kadaffi" (ibidem, 13). Nesse sentido, a Primavera Árabe líbia foi vista por Riad como uma oportunidade de derrubar um antigo inimigo e como um meio para construir uma imagem positiva de defensores do povo líbio, de modo a aumentar a sua legitimidade interna, abalada pela repressão aos protestos em sua Província Oriental, e por sua postura anti-revolucionária no Bahrein e em Omã. Este cenário de possibilidades de afastamento de ameaças externas e de ampliação da legitimidade doméstica para os governos em desenvolvimento, dialogam diretamente com o conceito de omnibalancing de David (1991).

O isolamento político regional e global da Líbia de Kadaffi, contribuiu para que a Arábia Saudita não tivesse grandes dificuldades em contribuir para a deposição do ditador líbio. Inicialmente, Riad utilizou-se do multilateralismo regional para este objetivo, solicitando em oito de março de 2011 ao Conselho de Segurança da ONU (CSNU) uma intervenção na Líbia, de modo a proteger os civis naquele país (AL BAIK; SALAMA, 2011). Pouco dias depois, a Liga Árabe pediu ao CSNU a imposição de uma zona de exclusão aérea sob a Líbia, com o mesmo propósito (AL-JAZEERA 2011). Esta pressão regional, o afastamento internacional de Kadaffi e o interesse de potências europeias, culminaram com a Resolução 1973 do CSNU que estabeleceu uma zona de exclusão aérea e autorizou o uso de todos os meios necessários para a proteção de civis (UN Resolution 1973 2011).

Com este aparato legal, a Organização do Tratado do Atlântico Norte 
$115 \mid$ InterAção

(OTAN), interviu na Líbia, contribuindo decisivamente para a queda de Kadaffi no final de outubro de 2011; indicando que o esforço político e diplomático de Riad para a queda do ex-ditador líbio, fora bem sucedido (BERTI e GUZANSKI 2014). Além de apoiar (politicamente) a intervenção da OTAN na Líbia, a Arábia Saudita vem dando suporte para grupos armados na Líbia que lutam contra facções islamistas (inspirados/afiliados da Irmandade Muçulmana) amparadas pelo Catar (KIRPATRICK 2015).

Além da tradicional percepção saudita que o fortalecimento regional da Irmandade Muçulmana represente uma ameaça a sua estabilidade interna, notamos o interesse de Riad em reduzir a crescente influência regional do Catar (evidenciado na luta por procuração na Líbia entre as duas nações) O pequeno Emirado, apesar de ter como base política-religiosa o Salafismo (de maneira similar à Arábia Saudita), tem construído uma relação próxima com o grupo islamista há décadas (ULRICHSEN 2014). Esta aproximação tem caráter puramente pragmático, uma vez que visa sobretudo contrabalancear a influência que Riad exerce sobre os grupos salafistas. Dessa forma, para Haykel: "de maneira simbiótica (...) Doha fornece significativo apoio financeiro e político, enquanto que a Irmandade Muçulmana dirige suas energias como um canal para projetar a influência regional do Catar (2013, 3, tradução livre). Apesar dessa disputa, Riad tem optado por evitar um confronto direto com Doha, uma vez que, conforme preconiza o omnibalancing, a atuação do Catar não se configura como uma ameaça primária à Arábia Saudita, devido a inegável superioridade de Riad (DAVID 1991).

No que diz respeito, à Primavera Árabe síria, observamos que Riad tem atuado ativamente para tentar derrubar o governo de Bashar Al-Assad. Mas o que faz Riad agir desta maneira? Tendo como base o esquema teórico do omnibalancing, vemos que a decisão de atuar externamente em prol da queda do 
116 | InterAção

regime de Assad, pode ser examinada a partir do posicionamento saudita a respeito de ameaças e oportunidades, nos níveis interno, regional e global:

(1) Internamente, a substituição do governo de Assad pró Irã xiita, por um sunita (aliado à Arábia Saudita), aumentaria a percepção interna identitária da liderança saudita no mundo sunita.

(2) Regionalmente, a derrubada do atual regime sírio representa uma redução do poder regional iraniano, e consequentemente uma diminuição das ameaças à segurança saudita. Igualmente, o fim do eixo Damasco-Teerã aponta para o arrefecimento da ameaça ao regime saudita, perpetrada pelo islamismo xiita revolucionário.

(3) Globalmente, o fato da administração síria ser mal vista pelo Ocidente (sobretudo pelo aliado EUA), impede maiores constrangimentos estruturais para ações sauditas contra este país.

Tendo como base as dinâmicas nestes três níveis analíticos, visando maximizar sua autonomia e segurança, e agindo de forma racional de modo a melhor atingir estes objetivos o regime da Casa de Al-Saud, deixou de lado sua tradicional posição de potência status quo para se engajar no conflito sírio (DAVID 1991, HINNEBUSCH 2003). Este envolvimento ocorreu no âmbito discursivo, multilateral, e bélico.

Inicialmente (agosto de 2011) Riad condenou duramente a atuação do regime sírio contra a sua população, afirmando que este governo deveria "parar a sua máquina de matar" e que sua repressão "não tinha nada a ver com religião, valores ou ética" (FLOCK 2011). Posteriormente, a Arábia Saudita decidiu agir no âmbito multilateral regional contra o regime sírio. No final de 2011, a partir de forte influência saudita, a Liga Árabe decidiu suspender a Síria da organização e aplicar sanções econômicas e políticas contra Damasco (AL- 
117 | InterAção

JAZEERA 2011). Esta medida, mesmo que a posteriori não tenha ocasionado o efeito esperado, sinaliza os esforços sauditas em isolar e enfraquecer o governo de Bashar Al-Assad.

Isto ocorre em razão da percepção pela elite saudita, do papel chave que a Síria possui como aliado fundamental, do inimigo e sempre ameaçador, Irã. Nesse sentido, para Gause, “o melhor modo de entender a política externa regional saudita é em termos de sua contenção à influência iraniana" $(2011,16)$. Dessa forma, enfraquecer o seu principal inimigo na região, constitui-se em um eixo central da política externa saudita.

A aliança entre Irã e Síria, também representa em aspecto macro, o núcleo do chamado "Eixo da Resistência", que além das duas nações, envolve os grupos de resistência palestina, Hamas e Hezbollah, e o apoio russo, e ocasionalmente chinês. Este bloco, anti-americano e anti-saudita, na dinâmica regional de poder contrabalanceia o eixo pró americano, que tem como centro a Arábia Saudita, o Egito e as monarquias do Golfo Pérsico. De acordo com Sallokh, Riad usando como pretexto o apoio às aspirações democráticas do povo da Síria, tem tentando derrubar o regime sírio, reorientando-o para o campo saudita-americano (2013).

A elite governamental saudita tende a conceber a sua disputa geopolítica regional (onde o Eixo da Resistência é um dos polos) com o Irã também como um tema que envolve a segurança de seu próprio regime, uma vez que entende que o Irã atua ativamente para desestabilizar o seu regime (GAUSE 2011). Nesse sentido, tendo como base as ideias do omnibalancing, esta percepção de ameaça interna, motivou a elite saudita a envolver-se fortemente em uma política anti-Assad.

O engajamento saudita na Síria também pode ser explicado a partir da constante necessidade de construção da legitimidade interna do regime dos Al- 
118 InterAção

Saud. O controle político sob uma Síria sunita, representaria um avanço na liderança da Arábia Saudita no mundo sunita e um revés para o xiismo iraniano. Analisando o simbolismo religioso para A Arábia Saudita e o Irã, Elakawi (2014) pontua que o controle político da religião é essencial para a legitimidade interna dos regimes de ambos os Estados, bem como para suas aspirações de hegemonias regionais. Ainda segundo o autor "essa legitimidade é necessária para a concentração do poder e para a hegemonia interna, e também configurase como um argumento para suas aspirações hegemônicas regionais $(2014,5)$.

Tendo a religião como arma ideológica, Riad busca exaltar a divisão entre sunitas e xiitas de modo a angariar apoio para seus aliados regionais e isolar o Irã e seus aliados árabes (GAUSE 2011). Dentro desse escopo, os protestos da Primavera Árabe síria, configuram-se como uma interessante ocasião para Riad procurar construir futuramente uma influência sob um país árabe e de maioria sunita Ennis e Momani (2013).

Desta forma, há uma manipulação da religião para fins políticos por parte da Arábia Saudita, a partir do uso do sectarismo religioso. Nesse sentido, Riad usa do sectarismo como um instrumento de política regional, controlando as divisões e sentimentos históricos entre sunitas e xiitas de modo a angariar apoio para seus aliados regionais e isolar o Irã e seus aliados árabes (GAUSE 2011). Para Ennis e Momani:

Visto através dessas lentes de sectarismo, e tentativas de contrabalancear a influência iraniana, os protestos na Síria representaram uma oportunidade para os Al-Saud. (...) Com uma população majoritariamente sunita, as revoltas na Síria foram vistas como uma chance de trazer de volta para a esfera de influência árabe, e sunita (2013, 1135-1136, tradução livre).

Nesse sentido, tendo como base o papel chave que uma Síria pró-Irã constituiu dentro do espectro de ameaças internas e externas à Riad, a elite saudita seguiu com sua campanha para derrubar o regime de Damasco. Em 
119 InterAção

fevereiro de 2012, a Liga Árabe (a partir de forte pressão saudita) solicitou uma intervenção onusiana na Síria (SCHMITT e WORTH 2012). O impasse no CSNU a respeito dessa possível intervenção na Síria (causado pelos vetos chineses e russos) fez a diplomacia saudita tomar uma medida extrema: negar-se a ocupar sua cadeira como membro rotativo no CSNU em novembro de 2013 (NICHOLS 2013).

Paralelamente a seu ativismo em fóruns multilaterais contra o regime de Assad, a Arábia Saudita tem atuado intensamente nos bastidores, apoiando grupos insurgentes na Síria. Primeiramente, Riad aguardou os EUA para que os dois países pudessem organizar de forma conjunta uma ação política para a Síria. Vendo a hesitação de Washington em estabelecer conexões com grupos insurgentes sírios, Riad decidiu agir por conta própria financiar e armar os rebeldes (STEINBERG 2014). Apesar do constrangimento externo causado pela dependência militar à esta grande potência, a diplomacia saudita, motivada por sua percepção do momento favorável para intervir indiretamente no conflito sírio, racionalmente tomou esta decisão. Comentando a racionalidade na política externa, Hinnebusch, em sua obra The International Politics of the Middle East afirma que: "a racionalidade na política externa, indica a razão do Estado, isto é, a escolha dos fins por meio de um cálculo de custo benefício e a adequação dos fins com os meios" $(2003,75)$.

Assim, de modo racional, a partir de 2012, a Arábia Saudita tem usado todo o seu poder econômico oriundo dos petrodólares para financiar grupos rebeldes sírios que lutam contra o governo de Assad. Segundo Sallokh, Riad tem dado suporte e financiado o Exército Livre da Síria, enquanto que permite as mobilizações de grupos salafistas-jihadistas via canais de televisão via satélite instaladas em solo saudita (2013).

A operacionalização desse suporte saudita aos rebeldes, ocorre de forma 
$120 \mid$ InterAção

coordenada com a vizinha e aliada Jordânia, que abre a sua fronteira junto à Síria para a passagem de insurgentes (HUBBARD 2014). Com este apoio saudita à oposição armada síria, vemos novamente a prerrogativa do omnibalancing de que prestar ajuda a favor de grupos insurgentes é um meio relativamente barato e eficaz para os Estados afirmarem o seu poder (DAVID 1991).

\section{CONSIDERAÇÕES FINAIS}

Dentro de suas ações externas durante a Primavera Árabe, constatou-se que a Arábia Saudita mais do que orientar-se pela lógica da busca por segurança estatal, guiou-se pelo empenho em garantir a estabilidade de seu regime, conforme sustenta a teoria do omnibalancing. Tendo como base esta averiguação, propusemos o seguinte problema de pesquisa: como o desejo de manutenção do regime de Riad guia a política externa saudita durante a Primavera Árabe? A partir do que foi exposto ao longo do trabalho, identificamos dois eixos que guiaram este propósito de conservação do status quo na Arábia Saudita: a retenção do poder regional do Irã e a repressão à ascensão política da Irmandade Muçulmana.

A contenção do Irã explica-se tanto pelo temor da ascensão regional deste país, hipoteticamente fortalecido pelo ganho de novos aliados herdados da Primavera Árabe (Egito, Iêmen e Bahrein), quanto pelas tentativas de Teerã em desestabilizar a política doméstica saudita, via apoio à população xiita saudita. A respeito da Irmandade Muçulmana, Riad teme que o crescimento regional do islamismo político do grupo, externamente possa enfraquecer as monarquias islâmicas similares a sua, enquanto que internamente, venha a fomentar o fortalecimento da vertente saudita da organização, representando 
$121 \mid$ InterAção

assim, uma ameaça doméstica à Casa dos Al-Saud. Desse modo, equilibrandose diante dessas ameaças internas e externas, Riad operacionalizou uma política externa a fim de garantir a manutenção de seu regime, ora apoiando política e economicamente a governos aliados (Tunísia, Egito, Jordânia, Marrocos, Omã e Iêmen), ora empregando esforços diplomáticos e logísticos para derrubar regimes inimigos (Líbia e Síria). Quando a elite saudita percebeu que o seu regime estaria sob ameaça com a queda do governo aliado do Bahrein, através de um possível spillover dos protestos xiitas para o seu território, conjugado com um aumento do poder iraniano, a Arábia Saudita não hesitou em usar a força militar para garantir a manutenção do status quo regional e doméstico.

Tendo essas considerações expostas, conclui-se que a política externa da Arábia Saudita orientou-se pragmaticamente para a manutenção e legitimidade de seu regime, através da contenção das ameaças internas e externas eclodidas por ocasião da Primavera Árabe. Em relação ao alcance das ações tomadas com esse desiderato, percebe-se que a política externa de Riad foi exitosa em quase todos os casos, mostrando a racionalidade dessas ações frente aos anseios de mudança propagados durante as revoltas populares na região.

\section{REFERÊNCIAS}

AL BAIK, D.; SALAMA, S. 2015. GCC calls for UN action on Lybia. Gulf News, 8 mai. 2011. Disponível em: [http://gulfnews.com/news/region/libya/gcccalls-for-un-action-on-libya-1.773101/]. Acesso em: 5 mar. 2014.

AL JAZEERA. 2011. Arab League decides to suspend Syria. Al Jazeera, 13 nov. 2011. Disponível em:

[http://www.aljazeera.com/news/africa/2011/03/201131218852687848.html/ ]. Acesso em: 5 mar. 2015.

2012. Saudi protest crackdown leaves two dead. Al Jazeera, 9 jul. 2012.

Disponível em: 
$122 \mid$ InterAção

[http://www.aljazeera.com/news/middleeast/2012/07/20127819561763436.ht $\mathrm{ml} /$ ]. Acesso em: 2 abr. 2015.

AL-RASHEED, Madawi. 2011. The Saudi response to the 'Arab spring': containment and co-option. Open Democracy, 10 jan. 2011. Disponível em: [https:/ / www.opendemocracy.net/5050/madawi-al-rasheed/saudi-responseto- $\%$ E2\%80\%98arab-spring $\%$ E2\%80\%99-containment-and-co-option/]. Acesso em: 5 mar. 2014.

BAYOUMY, Yara.; GHOBARI, Mohammed. Saudi suspends aid to Yemen after Houthi takeover - sources. Reuters, 4 de dezembro de 2014. Disponível em: [http://www.reuters.com/article/2014/12/04/us-yemen-saudi-aididUSKCN0JI10V20141204]. Acesso em 22 dez. 2015.

BERTI, B.; GUZANSKY, J. 2014. Saudi Arabia's foreign policy on Iran and the proxy war in Syria: toward a new chapter? Israel Journal of Foreign Affairs, v. 3, n. 2.

CONSELHO DE SEGURANÇA DAS NAÇÕES UNIDAS (CSNU). 2011. Resolução nº 1973, de 17 de março de 2011.

DAVID, Steven R. 1991. Explaning third world alignment. World Politics, v. 43, n. 2, p. 233-256.

ELAKAWI, Zaki. 2014. The geostrategic consequences of the Arab Spring. Open Democracy, 22 nov. 2014. Disponível em:

[https:/ / www.opendemocracy.net/arab-awakening/zaki-samyelakawi/geostrategic-consequences-of-arab-spring/]. Acesso em: 5 mar. 2015.

ENNIS, C. A.; MOMANI, B. 2013. Shaping the Middle East in the midst of the arab uprisings: Turkish and Saudi foreign policy strategies. Third World Quarterly, v. 34, n. 6, p. 1127-1144.

FAISAL, Turki Al. 2013. Saudi Arabia's new foreign policy doctrine in the aftermath of the arab awakening. King Faisal Center for Research and Islamic Studies, p. 1-10.

FLOCK, Elizabeth. 2011. Saudi King Abdullah to Syria: “Stop the killing machine". The Washington Post, Washington, 8 ago. 2011. Disponível em: [http://www.washingtonpost.com/blogs/worldviews/post/saudi-kingabdullah-to-syria-stop-the-killingmachine/2011/08/08/gIQASy3n2I_blog.html/]. Acesso em: 5 mar. 2015.

GAUSE, F. 2011. Saudi Arabia in the New Middle East. Council on Foreign Relations, dez. 2011. Disponível em: [http:/ / www.cfr.org/saudi-arabia/saudiarabia-new-middle-east/p26663/]. Acesso em: 5 mar. 2015. 
123 | InterAção

HINNEBUSCH, Raymond. 2003. The international politics of the Middle East. Manchester e Nova Iorque: Manchester University Press.

HUBBARD, Ben. 2014. Warily, Jordan assists rebels in Syria war. The New York Times, Nova Iorque, 10 abr. 2014. Disponível em: [http://www.nytimes.com/2014/04/11/world/middleeast/syria.html/]. Acesso em: 5 mar. 2015.

KIRPATRICK, David D. 2015. Saudies expand regional powers as other felts. The New York Times, Nova Iorque, 25 jan. 2015. Disponível em: [http:/ / www.nytimes.com/2015/01/26/world/middleeast/saudis-expandregional-power-as-others-falter.html?_r=0/]. Acesso em: 5 mar. 2015.

LAESSING, Ulf. 2011. Saudi Arabia says won't tolerate protests. Reuters, 5 mar. 2011. Disponível em:

[http://br.reuters.com/article/worldNews/idBRSPE84M04E20120523/]. Acesso em: 2 abr. 2015.

MAJIDYAR, Ahmad. 2013. Saudi Arabia's forgotten Shi'ite spring. AEI Outlook Series.

Mc DOWALL, Angus. 2012. Ocidente e Golfo prometem US\$4 bi em ajuda ao Iêmen contra Al Qaeda. Reuters, 23 de maio de 2012. Disponível:

[http:/ / br.reuters.com/article/worldNews/idBRSPE84M04E20120523/]. Acesso em: 5 mar. 2015

MURPHY, Caryle. 2011. GCC to set up \$20bn bailout fund for Bahrain and Oman. The National.

NG, Aaron. 2011. In Focus: Al Qaeda in the Arabian Peninsula (AQAP) and Yemen Uprisings. Counter Terrorist Trends and Analysis, v. 3, n. 6, p.1-4.

NICHOLS, Michelle. 2013. Saudi rejects U.N. Security Council seat, opening way for Jordan. Reuters, 12 nov. 2013. Disponível em:

[http://www.reuters.com/article/2013/11/12/us-un-saudi-jordanidUSBRE9AB14720131112/ ]. Acesso em: 5 mar. 2015.

NONNEMAN, Gerd. 2005. “Determinants and patterns of Saudi foreign policy. "omnibalancing" and "relative autonomy" in multiple environments". In: AARTS, P.; NONNEMAN, G. Saudi Arabia in balance: political economy, society, foreign affairs. Hurst e Company: Londres.

OMRAN, Ahmed Al. 2013. Saudi Arabia: a new mobilization. In: what does the gulf hink about the arab awakening? European Council on Foreign Relations. 
$124 \mid$ InterAção

RIEGER, Rene. 2013. In Search of stability Saudi Arabia and the Arab Spring. In: Saudi Arabia and the Arab Uprising: national, regional and global responses, Gulf Research Meeting.

SALISBURY, Peter. 2012. Mixed messages on reform. Middle East Economic Digest, p. 5-11.

SAUDI GAZETTE. 2015. Causeway to Bahrain reopens. Saudi Gazette, 15 abr. 2015. Disponível em:

[http:// www.saudigazette.com.sa/index.cfm?method=home.regcon\&contentI $\mathrm{D}=2011041598318 /$ ]. Acesso em: 5 mar. 2015.

SALLOUKH, Bassel F. 2013. The arab uprisings and the geopolitics of the Middle East. The international spectator, v. 48, n. 2, p. 32-46.

SCHMITT, E.; WORTH, R. F. 2012. With arms for Yemen rebels, Iran seeks wider Mideast role. The New York Times, Nova Iorque, 15 mar. 2012. Disponível em:

[http://www.nytimes.com/2012/03/15/world/middleeast/aiding-yemenrebels-iran-seeks-wider-mideast-role.html?pagewanted=all\&_r=0/]. Acesso em: 5 mar. 2015.

SOUBRIER, Emma. 2013. Regional disorder and new geo-economic order Saudi security strategies in a reshaped Middle East. In: Saudi Arabia and the Arab Uprising: National, Regional and Global Responses, Gulf Research Meeting.

STACK, L.; MacFARQUAHAR, N. 2012. Arab League steps up pressure on Syria and call for UN help. The New York Times, Nova Iorque, 12 fev. 2012. Disponível em:

[http:/ / www.nytimes.com/2012/02/13/world/middleeast/arab-leaguerequests-un-peacekeepers-for-syria.html/]. Acesso em 5 mar. 2015.

STEINBERG, Guido. 2014. Leading the counter-revolution: Saudi Arabia and the Arab Spring. SWP Berlin, p. 1-27.

ULRICHSEN, Kristian. 2014. Qatar and the Arab Spring: Policy drivers and regional implications. Carnegie Endowment for International Peace.

VISENTINI, Paulo. 2014. O grande Oriente Médio- Da descolonização à Primavera Árabe. Rio de Janeiro, RJ: Campus Elsevier. 